\title{
Comprehensive Study on Machinability of Titanium Composite
}

\author{
Basim A. Khidhir \\ Department of Production Engineering \& Metallurgy, Technical College of Engineering, Sulaimani Polytechnic \\ University, Kurdistan Region, Iraq \\ Email: basim.khidhir@spu.edu.iq
}

Received 16 August 2015; accepted 28 January 2016; published 1 February 2016

Copyright (C) 2016 by author and Scientific Research Publishing Inc.

This work is licensed under the Creative Commons Attribution International License (CC BY).

http://creativecommons.org/licenses/by/4.0/

(c) (i) Open Access

\begin{abstract}
Metal framework composites have higher mechanical properties in examination to metals over an extensive variety of working conditions. This makes them an alluring alternative in swapping metals for different building applications. The present review is a study on the influence of composite titanium on the cutting parameters, mechanical behavior, reinforcements, structure and nanostructure. This review will provide an understanding into selecting the optimum machining parameters for machining titanium composites. It's also an attempt to give brief explanation by suitably machining the titanium composite which can be made reasonable.
\end{abstract}

\section{Keywords}

Titanium Composite, Reinforcement, Cutting Speed, Feed Rate, Depth of Cut, Surface Finish, Machinability

\section{Introduction}

Composite materials comprise of two or more materials that contrast in synthetic and physical properties and are not dissolvable in each other. The framework stage is the essential constituent in a composite material that gives burden exchange and structural integrity while the fortification of upgrade mechanical properties [1]. Natural, inorganic or metallic are three types of matrix and reinforcement materials. Both long and short types of fibers or particulates are the most well-known types of reinforcement materials. Important properties of composite materials are: improved strength \& stiffness, excellent fatigue resistance, high heat resistant, high wear resistant, high corrosion resistant, low weight, etc. It is likely to attain preferred qualities for a particular application if the metal matrix is suitably arranged and its reinforcement is increased. Titanium, magnesium and aluminum are matrix materials in Metal Matrix Composites (MMC). Fortifying materials in MMC are silicon carbide, boron 
carbide, alumina and graphite as particles, short filaments (whiskers) or long fibers. In Titanium Metal Matrix Composites (TiMMC), matrix material is titanium and reinforcement materials are silicon carbide, aluminum oxide, boron carbide, graphite, etc. in the form of fibers, whiskers \& particles. For more tolerance and precision, a need often exists for machining. Machining characteristics depend on the reinforcement material, kind of reinforcement (particle or whisker), distribution of reinforcement in the matrix, and volume fraction of the reinforcement and matrix. Machining composite is more different than metal machining due to presence of hard and brittle reinforcements. The fundamental issue in composite's machining is the high instrument wear, which prompts an uneconomical creation process or makes the procedure impossible. Accordingly, machining of composite materials forces unique requests on the geometry and wear resistance of the cutting instruments [1]. This paper examines the vital parts of machining of titanium metal framework composites TiMMC.

\section{Effect of Cutting Parameters}

In the literatures, very little research studies are found on the machining of TiMMC. One of the benefits of TiMMC is that its microstructure is composed of titanium Alpha and Beta phases, and of hard particles of TiC. Therefore, in the existence of plastic strain, it results in the breaking of the hard particles change of these phases. This means that studying the formed chip will provide information on the displacement of plastic strain of each zone of the chip profile. Roland Bejjani [2] provides a practical recommendation for determining the cutting parameters and for evaluating different cutting tools for machining TiMMC. Following experimental work and analysis, he found that cutting TiMMC at higher speeds was more efficient and productive since it increased tool life. This is in opposition to most materials, where higher cutting speeds reduce tool life. This phenomenon of efficient cutting at higher speeds was explained by the different tool/particles behavior. He found that at higher speeds, fewer hard TiC particles were broken, resulting in reduced tool abrasion wear as shown in Figure 1.

After a careful examination of the chips morphology, observing that in general fewer particles were broken in the chips when cutting at high speeds. Figure 1 shows an example of a particle located between two shear bands in a chip cut at high speed. In general, if a particle is located inside the segment's bulk and not in-line with the shear band (as in Figure 1), then this region of low plastic strain will not induce high enough stresses to break the particle. Therefore, since the particle will be just displaced and not broken (as in the case of Figure 2), this will result in less abrasion wear on the tool.

C.L. Kuo et al. [3] carried out studies to assess the effect of cutting quickness (Ti/CFRP/Al: 30/120/120 and $36 / 144 / 144 \mathrm{~m} / \mathrm{min})$ and feed rate $(0.05,0.08,0.12$ and $0.15 \mathrm{~mm} / \mathrm{rev})$ on work piece surface integrity following single-shot drilling of multilayer metallic composite stacks (Ti-6Al-4V/CFRP/Al-7050) using CVD diamond coated tooling. They found that when operating with the lower cutting speed set of 30/120/120 $\mathrm{m} / \mathrm{min}$ and a feed rate of $0.08 \mathrm{~mm} / \mathrm{rev}$, average hole surface roughness (Ra) was $\sim 0.60,0.87$ and $0.27 \mu \mathrm{m}$ in the Ti, CFRP and Al layers respectively after 30 holes. Roughness values in the stack increased to $0.84,1.6$ and $0.43 \mu \mathrm{m}$ Ra when employing the higher cutting speed of 36/144/144 m/min, with the drill lasting only 20 holes. Microhardness

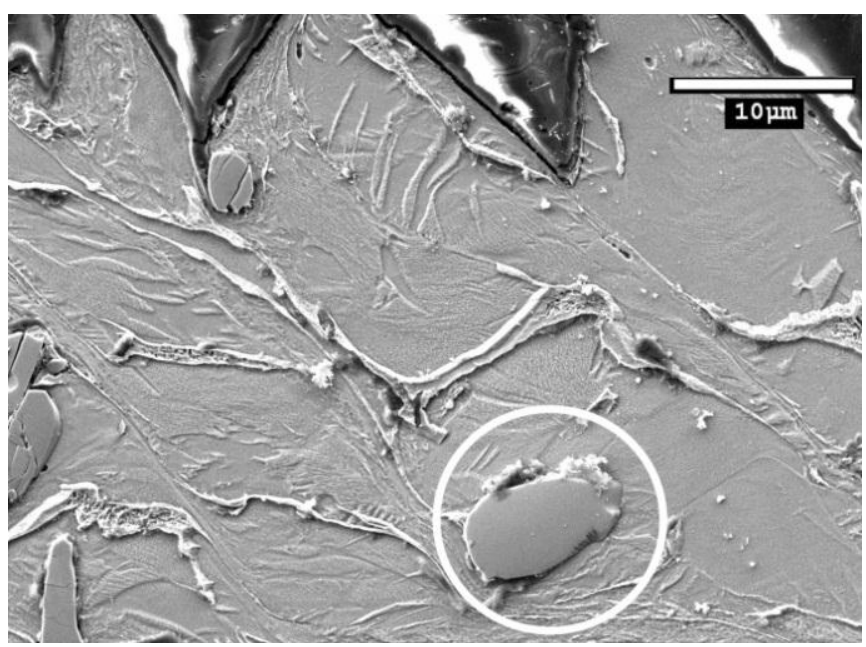

Figure 1. Chip morphology at $\mathrm{v}=180 \mathrm{~m} / \mathrm{min}$ showing a particle which did not break after the chip formation [2]. 


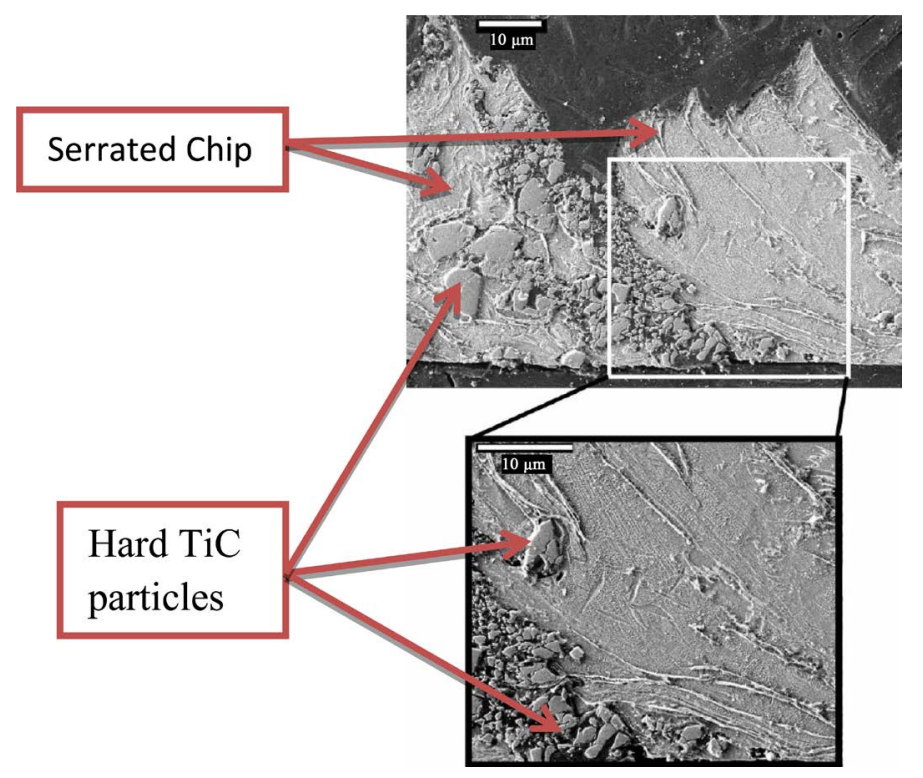

Figure 2. Chip morphology at $\mathrm{v}=60 \mathrm{~m} / \mathrm{min}$ showing a particle broken into many other smaller particles [2].

depth profile evaluation of the machined surfaces showed no appreciable variation in both the Ti and $\mathrm{Al}$ material, irrespective of cutting conditions. Matrix cracking and burn were apparent in the CFRP layer as feed rate increased due to greater wear.

Roland Bejjani et al. [4] focuses on comparing the performance of different tools under different cutting parameters to find the optimum cutting conditions within the constraints of maximum surface integrity and tool life. It found that Poly- Crystalline-Diamond (PCD) tools substantially outperform coated carbide tools. Moreover, chip formation has been carefully studied to understand the interaction of the added Titanium Carbide (TiC) particles with the cutting tool. Contrary to other materials, cutting of TiMMC at higher speeds was found to be more advantageous and resulted in a higher tool life. Analysis of the chip morphology also revealed that the chip formation at high speeds is clearly different from that at lower speeds, suggesting a different cutting mechanism.

\section{Effect of Mechanical Properties}

The characterization of such composite materials needs knowledge of a number of physical parameters. J. H. Zhu et al. [5] investigated the Mechanical behavior of both the Ti-6Al-4V combination and the Ti-6Al-4V composite such as their ductile and creep properties at $538^{\circ} \mathrm{C}$ after they were fortified with 10 wtpctTiC particulates created by cool and hot isostatic pressing (CHIP). They found that the yield quality (YS) and extreme rigidity (UTS) of the composite were more noteworthy than those of the matrix compound at the strain rates extending from more or less $10-5$ to $10-3 \mathrm{~s}^{-1}$, and the creep resistance of the composite was better than that of the matrix compound. While, the extension of the composite material was recognizably lower than that of the matrix compound. The outcome of the tensile-tested matrix compound indicated dimpled breakage, while the creep- tried matrix compound showed especially interlath and intercolonycracking. The failure of the tensile- tested and creep-tested composite material was controlled by the cleavage failure of the particulates, which was followed by the bendable fracture of the matrix.

Another study conducted by Ye-Xia Qin et al. [6] investigated the mechanical features and fracture mechanization of in situ blended titanium composite by uniaxial strain at high temperatures. Their study demonstrates that the ultimate tensile strength reduces and the ductility increases as temperature is increased. As compared to the matrix compound, extreme tensile strength of the composite was enhanced clearly in light of the fact that the in situ created reinforcement are exceptionally steady at high temperatures and can fortify the matrix combination successfully. The fracture behavior was contingent on temperature. The composites fall flat at low strain at room temperature because of the break of the fortifications. As temperature becomes higher, voids are prone to start and grow at the interface between the reinforcement and the matrix combination, and their mixture inevitably prompts the fracture of the composites. As a conclusion, the debonding between the reinforcement and the 
matrix compound turns into the principle purpose behind the composites failure.

In Lv Xiao et al. [7] study, the pliable properties of high-temperature titanium matrix composites strengthened with hybrid reinforcements was tested by using common casting and hot working technologies. It is found out that composite's ultimate strength is noticeably heightened under all conditions but it lessens when the strain rate is reduced. The outcome of the abovementioned study demonstrates that the interfacial debonding is more radical and lessens the composites' strength. Their outcome demonstrates that at higher temperature or lower strain rate, interfacial debonding is more drastic and diminishes the strengths of composites. In addition, it is found out that under creep-rupture conditions, the materials are embrittled.

In the study of Threrujirapapong et al. [8], the microstructure and mechanical properties of extruded pure Ti matrix composites reinforced with TiC particles were assessed. The composite prepared by spark plasma sintering (SPS) and hot extrusion a powder metallurgy (P/M) titanium matrix composite (TMC) reinforced with low cost carbon black. Throughout the SPS process, Carbon dark particles were added for the in situ arrangement of TiC dispersoids. Two sorts of titanium (Ti) powders, sponge and fine Ti, were covered with carbon dark particles by means of a wet procedure utilizing a zwitterionic solution containing carbon dark spheres. They found out that by adding a small amount of carbon dark at 0:070:16 mass\%, the mechanical properties of these composites were improved. The increments in the yield stress of the expelled spong and fine TMC were 70.0 and 291 MPa, whereas the rigidity increments were 67 and $231 \mathrm{MPa}$, respectively, contrasted with those of extruded pure Ti with no fortification. After tensile testing, they noticed fractured surfaces of TMC samples.

Zanaib. Y. Shnean [9] prepared a composite material made out of high thickness polyethylene and inorganic color (carbon dark and titanium dioxide). By utilizing diverse measures of carbon dark and titanium dioxide, (2 15) wt.\% were included as filler. The outcomes demonstrate that the utilization of colors, carbon dark and $\mathrm{TiO}_{2}$ in suitable ratios proportions give a dependable change in the mechanical properties. The weight fraction of the carbon blacks and titanium dioxide ranged from 0.0 up to $15 \mathrm{wt} . \%$ with the high thickness polyethylene. It was found that the of the composite's resistivity was lessened after discharging a high voltage through it. Carbon dark and titanium dioxide-high thickness polyethylene composites are significantly different from the neat highdensity polyethylene measured in the frequency range. It is found that thermal properties of both carbon black and titanium dioxide/high-density polyethylene composites are better than that of the neat high-density polyethylene.

\section{Effect of Reinforcement}

The use of titanium composite material not only permits a useful reduction in structural weight, but also virtually eliminates fatigue and corrosion handicaps and offers flexible and cost-efficient manufacturing possibilities with high structural integrability. A. Fink and B. Kolesnikov [10] study one strategy for expanding mechanical joint productivity involves the fortification of the joining parts with slim metal overlays. The results of the experiment demonstrate that bearing strength and blasted joint strength were significantly increased. The conversion from composite to hybrid titanium composite material has been developed through an efficient design; this process empowers the local utilization of metal fortification procedures in structure interconnections and force transmission points. The presence of the reinforcement affects the machinability of composites substantially. The hard carbide particles in the matrix cause issues, for example, excessive tool wear. The size and the rate volume fraction of the fortification play a significant role on the machinability of composites. Surface completion is fundamentally reliant on the average size and volume fraction of the particles.

Experimental and numerical study conducted by Camanho et al. [11] investigated the mechanical reaction of bolted joints manufactured using new hybrid composite overlays by substituting the CFRP plies with titanium plies. The local hybridization of the material is suggested to build the effectiveness of the bolted joints in CFRP structures. Two demonstrating procedures, taking into account non-straight limited component strategies, are proposed for the investigation of the bolt-bearing and transition regions of the hybrid laminates. The numerical and test results show that the utilization of hybrid composites can definitely increase the strength of CFRP bolted joints and along these lines expand the effectiveness of this sort of association.

A. Fink et al. [12] conducted an experiment to investigate the mechanical reaction and the industrial manufacturability of CFRP-titanium hybrid laminates utilizing a sample of a spacecraft payload connector. The local hybridization with metal within botled joint regions of composite laminates is proven to be a viable technique for expanding the mechanical joint efficiency of highly loaded bolted joints. 
In Hua-Xin Peng's [13] study, a titanium metal network composites (TiMMCs) fortified by continuous silicon carbide fibers for aerospace uses was developed. TiMMCs manufactured by the merging of matrix-coated fiber (MCF) technique offer ideal properties because of the subsequent uniform fiber distribution, slightest fiber damage and fiber volume fraction control. The consolidation of Ti-6Al-4V matrix-coated SiC fibers during vacuum hot pressing was investigated in the abovementioned study. Experiments were carried out on multi-ply MCFs under vacuum hot pressing (VHP). As opposed to the greater part of existing studies, the fiber arrangement has been carefully controlled either in square or hexagonal arrays all through the solidified sample. This has empowered the dynamic consolidation behavior of MCFs to be demonstrated by eliminating the fiber re-arrangement during the VHP process.

\section{Effect of Structure and Nano Structure Transmission}

Many articles show that Nano structure composites can range very high hardness values due to the mixture of a Nano structure phase of a hard compound (typically titanium) inside an amorphous matrix. In D. MartínezMartínez's [14] study, the microstructure and chemical structure of the coatings were investigated by transmitting electron k. microscopy, nuclear force microscopy (AFM), electron diffraction, X-ray diffraction, X-ray photoelectron spectroscopy and electron energy loss spectroscopy. They noticed, for an unadulterated Argon climate, a microstructure constituted by little grains $(10-20 \mathrm{~nm})$ of a TiC stage embodied into an undefined framework. AFM parallel force mapping demonstrates a strong frictional difference between the two stages. At the point when nitrogen is used in the gas stage of the preparation process, the granular microstructure is not noticed, whereas the chemical composition is enriched in undefined nonstoichiometric $\mathrm{CNx}$ phases (a-CNx) with diverse content of nitrogen $(0.5 \mathrm{~V} \times \mathrm{V} 0.7)$. They related the kind of structure and chemical bonding of the Ti-C-N films with the tribological properties at the minuscule level so as to set up the amalgamation conditions prompting the nanocomposite construction.

Karolina Jurczyk et al. [15] presented an examination on the viability of nanostructured titanium-10 wt.\% 45S5 Bioglass-1 wt.\% Ag composite foams as a novel class of antibacterial materials for medicinal uses. Using a combination of mechanical alloying and a "space-holder" sintering process, the Ti-based composite foams were prepared. In the first step, the Ti-10 wt.\% 45S5 Bioglass-1 wt.\% Ag powder blended by mechanical alloying and annealing blended with $1.0 \mathrm{~mm}$ of diameter of saccharose crystals was finally compacted as pellets. In the following step, the saccharosecrystals were dissolved in water, leaving open spaces encompassed by metallic-bioceramicscaffold. The sintering of the scaffold prompts froth creation. It was concluded that 1:1 Ti-10 wt.\% 45S5 Bioglass-1 wt.\% Ag/sugar proportion prompts absorbencies of around 70\% with pore measurement of around $0.3-1.1 \mathrm{~mm}$. The estimation of the compression strength for the Ti-10 wt.\% 45S5 Bioglass-1 wt.\% Ag froth with $70 \%$ porosity was $1.5 \mathrm{MPa}$ and the Young's modulus was $34 \mathrm{MPa}$. Silver adjusted Ti-10 wt.\% 45S5 Bioglass composites have magnificent antibacterial activities against Staphylococcus aureus. Permeable Ti-10 wt.\% 45S5 Bioglass-1 wt.\% froth could be a conceivable contender for medical implants uses.

In study of Nabawia A. El-Zaher et al. [16], poly (methyl methacrylate)/titanium oxide nanoparticles (100/0, 97.5/2.5, 95/5, 92.5/7.5, 90/10 and 0/100 wt/wt.\%) composites were prepared to be utilized as bioequivalent materials as indicated by their significance expansive commonsense and restorative applications. Thermal properties and X-ray diffraction analyses were utilized to describe the composite's structure properties. The results which were obtained indicated varieties in the glass transition temperature (Tg), the melting temperature ( $\mathrm{Tm})$, shape and region of thermal peaks which were credited to the distinctive degrees of crystallinity and the presence of associations in the middle of $\mathrm{PMMA}$ and $\mathrm{TiO}_{2}$ nanoparticle particles. The XRD patterns indicated honing of peaks at diverse convergances of nano- $\mathrm{TiO}_{2}$ powder with PMMA. This demonstrated changes in the crystallinity/amorphosity proportion, furthermore recommended that the miscibility between the shapeles sconstituents of homopolymers PMMA and nano- $\mathrm{TiO}_{2}$ powder is feasible. The outcomes demonstrated that nano$\mathrm{TiO}_{2}$ powder blend with PMMA can enhance the thermal steadiness of the homo-polymer under study, prompting interesting technological uses.

Yu. Ryabkov [17] created titanium carbide-silicide $\mathrm{Ti}_{3} \mathrm{SiC}_{2}$ stage with crystal lattice shaped by alternate basic blocks with the block thickness in the order of $1 \mathrm{~nm}$, by the strategy based on the carbo-thermal diminishment of titanium and silicon oxides and high temperature processing of titanium carbide in $\mathrm{SiO}$ vapors. They showed that the $\mathrm{Ti}_{3} \mathrm{SiC}_{2}$ compound (regarded as a layered nanocomposite) displays the novel mix of properties which are non-ordinary for traditional ceramic materials. Specifically, the crystal construction and chemical changes dem- 
onstrated an increment in the paramagnetic constituent of magnetic defenselessness, which can be ascribed to titanium (III). They found that the titanium carbide-silicide stage with layered structure has antiferromagnetic properties.

\section{Conclusions}

Since data on the machinability of TiMMC is very limited in the open literature. Machinability remains still challenging due to the distribution and orientation of reinforcement in the matrix and non-homogeneous and anisotropic nature of composite as a whole. Also, there is a lack of research on the association between cutting parameters and workpiece solidifying. A large portion of the examinations conducted on the machinability of titanium amalgams were in light of different cutting conditions, which made it hard to compare results from diverse authors. Contrasted with metals, composite materials have better particular properties: higher strength than weight proportion, high firmness and great damage resistance over an extensive variety of working conditions, making them an appealing choice in substituting traditional materials for numerous engineering uses. It is essential to investigate the relationship between the cutting parameters, the induced workpiece deflection and prattle, and the dynamic cutting strengths created. By selecting the machining parameters suitably, machinability of TiMMC can be made economical. From previous studies the following can be concluded:

1) Adding hard $\mathrm{TiC}$ increases cutting speed, fewer particles are broken, resulting in reduced tool abrasion wear which improves tool life.

2) Increasing feed rate leads to greater wear.

3) The primary purpose behind the composites failure is the debonding between the fortifications and the matrix compound.

4) Cleavage failure of the particulates may be a reason for the ductile fracture of the matrix.

5) Thermal properties of carbon black and titanium dioxide/high-density polyethylene composites are better than the neat high-density polyethylene.

6) The size and the proportion volume fraction of the fortification play a significant role in the composites machinability.

Composite's machinability is affected by fortification’s size and the proportion volume fraction.

\section{References}

[1] Jain, P.K., Soni, S.C. and Baredar, P.V. (2014) Review on Machining of Aluminium Metal Matrix Composites. Material Science Research India, 11, 114-120. http://dx.doi.org/10.13005/msri/110204

[2] Bejjani, R. (2012) Machinability and Modeling of Cutting Mechanism for Titanium Metal Matrix Composites. PhD Dissertation, Mechanical Engineering Department, Polytechnic School of Montreal, Montreal.

[3] Kuoa, C.L., Sooa, S.L., Aspinwalla, D.K., Thomasb, W., Bradley, S., Pearsonc, D., Saoubid, R. and Leahye, W. (2014) The Effect of Cutting Speed and Feed Rate on Hole Surface Integrity in Single-Shot Drilling of Metallic-Composite Stacks. Procedia CIRP, 13, 405-410. http://dx.doi.org/10.1016/j.procir.2014.04.069

[4] Bejjani, R., Balazinski, M., Shi, B., Attia, H. and Kishawy, H. (2011) Machinability and Chip Formation of Titanium Metal Matrix Composites. International Journal of Advance Manufacturing System, IJAMS, 13, 1.

[5] Zhu, J.H., Liaw, P.K., Corum, J.M. and McCoy Jr., H.E. (1999) High-Temperature Mechanical Behavior of Ti-6Al-4V Alloy and $\mathrm{TiC}_{\mathrm{p}} / \mathrm{Ti}-6 \mathrm{Al}-4 \mathrm{~V}$ Composite. Metallurgical and Materials Transactions A, 30, 1569-1578. http://dx.doi.org/10.1007/s11661-999-0094-9

[6] Qin, Y.-X., Lu, W.-J., Sheng, X.-F., Yang, Z.-F. and Zhang, D. (2003) Mechanical Properties of in Situ Synthesized Titanium Matrix Composites at Elevated Temperature. Materials Transactions, 44, 2282-2287. http://dx.doi.org/10.2320/matertrans.44.2282

[7] Xiao, L., Lu, W.J., Qin, J.N., Zhang, D., Wang, M.M., Zhu, F. and Ji, B. (2008) High-Temperature Tensile Properties of in Situ-Synthesized Titanium Matrix Composites with Strong Dependence on Strain Rates. Journal of Materials Research, 23, 3066-3074. http://dx.doi.org/10.1557/JMR.2008.0378

[8] Threrujirapapong, T., Kondoh, K., Imai, H., Umeda, J. and Fugetsu, B. (2009) Mechanical Properties of a Titanium Matrix Composite Reinforced with Low Cost Carbon Black via Powder Metallurgy Processing. Materials Transactions, 50, 2757-2762. http://dx.doi.org/10.2320/matertrans.MA200906

[9] Shnean, Z.Y. (2012) Mechanical and Physical Properties of High Density Polyethylene Filled with Carbon Black and Titanium Dioxide. Diyala Journal of Engineering Sciences, 5, 147-159.

[10] Fink, A. and Kolesnikov, B. (2005) Hybrid Titanium Composite Material Improving Composite Structure Coupling. 
Proceedings of the European Conference on Spacecraft Structures, Materials and Mechanical Testing 2005 (ESA SP-581), Noordwijk, 10-12 May 2005.

[11] Camanho, P.P., Fink, A., Obst, A. and Pimenta, S. (2009) Hybrid Titanium-CFRP Laminates for High-Performance Bolted Joints. Composites Part A: Applied Science and Manufacturing, 40, 1826-1837. http://dx.doi.org/10.1016/j.compositesa.2009.02.010

[12] Fink, A., Camanho, P.P., Andrés, J.M., Pfeiffer, E. and Obst, A. (2010) Hybrid CFRP/Titanium Bolted Joints: Performance Assessment and Application to a Spacecraft Payload Adaptor. Composites Science and Technology, 70, 305317. http://dx.doi.org/10.1016/j.compscitech.2009.11.002

[13] Peng, H.-X. (2005) Manufacturing Titanium Metal Matrix Composites by Consolidating Matrix Coated Fibres. Journal of Materials Science and Technology, 21, 647-651.

[14] Martínez-Martínez, D., Sánchez-López, J.C., Rojasa, T.C., Fernández, A., Eaton, P. and Belin, M. (2005) Structural and Microtribological Studies of Ti-C-N Based Nanocomposite Coatings Prepared by Reactive Sputtering. Thin Solid Films, 472, 64-70. http://dx.doi.org/10.1016/j.tsf.2004.06.140

[15] Jurczyk, K., Adamek, G., Kubicka, M.M., Jakubowicz, J. and Jurczyk, M. (2015) Nanostructured Titanium-10 wt\% 45S5 Bioglass-Ag Composite Foams for Medical Applications. Materials, 8, 1398-1412. http://dx.doi.org/10.3390/ma8041398

[16] El-Zaher, N.A., Melegy, M.S. and Guirguis, O.W. (2014) Thermal and Structural Analyses of PMMA/TiO 2 Nanoparticles Composites. Natural Science, 6, 859-870. http://dx.doi.org/10.4236/ns.2014.611083

[17] Ryabkov, Y., Istomin, P. and Chezhina, N. (2001) Structural Design and Properties of Layered Nanocomposite Titanium Carbide-Silicide Materials. Materials Physics and Mechanics, 3, 101-107. 